\title{
Estimating deaths due to medical error: the ongoing controversy and why it matters
}

\author{
Kaveh G Shojania, ${ }^{1}$ Mary Dixon-Woods ${ }^{2}$
}

'Department of Medicine, Centre for Quality Improvement and Patient Safety, University of Toronto, Toronto, Ontario, Canada ${ }^{2}$ Cambridge Centre for Health Services Research, University of Cambridge, Institute of Public Health, Cambridge, UK

\section{Correspondence to} Dr Kaveh G Shojania, Sunnybrook Health Sciences Centre, Room H468, 2075 Bayview Avenue, Toronto, Ontario, Canada M4N 3M5; kaveh.shojania@sunnybrook.ca

Accepted 26 September 2016 Published Online First 12 October 2016

\section{SLinked}

http://dx.doi.org/10.1136/ bmjqs-2015-004849

\section{CrossMark}

To cite: Shojania KG, Dixon-Woods M. BMJ Qual Saf 2017;26:423-428.
One important reason for the widespread attention given to the 1999 US Institute of Medicine (IOM) report To Err Is $H_{u m a n}{ }^{1}$ lie in its estimate that medical error was to blame for 44 000-98000 deaths each year in the US hospitals. This striking claim established patient safety as a public concern, strengthened the case for improving the science underlying safety and motivated providers, policymakers, payers and regulators to take safety seriously. Some did express disquiet about the validity of the figures cited, ${ }^{2}$ including one of the principal investigators of the two studies that provided the data for these estimates. ${ }^{3}$

A decade and a half later, Makary and Daniel $^{4}$ attribute an even higher toll to medical error: 251454 deaths in US hospitals per year, making, they say, medical error the third-leading cause of death in the USA. Unsurprisingly, this claim generated widespread coverage in multiple media channels. It also ignited scientific controversy about the basis of the estimate and the role of mortality as a patient safety indicator (PSI). In this paper, we address this controversy and why it matters. We propose that the new estimate is very likely to be wrong. Not only is it wrong, it risks undermining rather than strengthening the cause of patient safety.

\section{THE NEW PAPER IS NOT A STUDY}

Though the paper by Makary and Daniel was widely cited as 'a study', it presented no new data nor did it use formal methods to synthesise the data it used from previous studies. The authors simply took the arithmetic average of four estimates since the publication of the IOM report, including one from HealthGrades, ${ }^{5}$ a for-profit company that markets quality and safety ratings, a report from the US Office of the
Inspector General (OIG) ${ }^{6}$ and two peerreviewed articles (table 1). ${ }^{8}$ The paper did not apply any established methodology for quantitative synthesis nor did it include a discussion either of the intrinsic limitations of the studies used or of the errors associated with the extrapolation process. To bolster their claims, Makary and Daniel did highlight the agreement between their estimates and that of a similar analysis published a few years ago by James. ${ }^{9}$ The apparent consensus is not, however, surprising, since they use mostly the same studies (listed in table 1 , together with a more recent analysis commissioned by the Leapfrog $\operatorname{group}^{10}$ ).

\section{ISSUES WITH THE STUDIES ON WHICH ESTIMATES OF DEATHS DUE TO MEDICAL ERROR ARE BASED}

Some of the widely quoted estimates of deaths due to medical error, including the IOM estimates, ${ }^{1}$ Makary and Daniel ${ }^{4}$ and James, ${ }^{9}$ are based on studies that in fact did not set out to estimate the rate of mortality linked to medical error. Instead, these primary studies sought to measure the prevalence of harm from medical care (ie, adverse events).

Consistent with their primary purpose, these studies included no methodology for making judgements about the degree to which adverse events played a role in any deaths that subsequently ensued. For instance, a patient admitted to the intensive care unit with multisystem organ failure from sepsis might develop a drug rash from an antibiotic to which he has exhibited a past allergic reaction. This patient has certainly experienced a preventable adverse event. But, if the patient eventually dies of progressive organ dysfunction a week after the antibiotic was changed, the medical error probably did not cause the death. An error that has 
Table 1 Studies generating estimates of deaths due to medical error*

\begin{tabular}{|c|c|c|c|}
\hline Study & Study features & $\begin{array}{l}\text { Deaths contributed } \\
\text { or caused by } \\
\text { medical error }\end{array}$ & $\begin{array}{l}\text { Limitations relevant to estimating } \\
\text { deaths due to medical error } \\
\text { Inclusion in estimate of deaths due } \\
\text { to medical error }\end{array}$ \\
\hline $\begin{array}{l}\text { Office of the Inspector } \\
\text { General }{ }^{6} \text { (used by Makary } \\
\text { and Daniel }{ }^{4} \text { and by James }{ }^{9} \text { ) }\end{array}$ & $\begin{array}{l}838 \text { hospitalisations involving } 780 \text { Medicare } \\
\text { beneficiaries randomly selected from the total } \\
\text { of } 999645 \text { Medicare beneficiaries discharged } \\
\text { from acute care hospitals during October } 2008\end{array}$ & 12 & $\begin{array}{l}\text { No stated method for judging the causal } \\
\text { relationship between preventable adverse event } \\
\text { and eventual death. }\end{array}$ \\
\hline $\begin{array}{l}\text { Office of the Inspector } \\
\text { General }{ }^{11} \text { (used by James }{ }^{9} \text { ) }\end{array}$ & $\begin{array}{l}278 \text { Medicare hospitalisations of at least } \\
24 \text { hours randomly sampled from the } 2549 \\
\text { total discharges from } 24 \text { hospitals in two } \\
\text { counties during } 1 \text { week in August } 2008 \text {. }\end{array}$ & 3 & $\begin{array}{l}\text { Very small number of deaths. } \\
\text { Study population does not include some } \\
\text { patient populations at lower risk of death (eg, } \\
\text { younger, non-Medicare patients), but } \\
\text { extrapolation includes these patients as if they } \\
\text { had same risk of death. } \\
\text { No assessment of preventability for adverse } \\
\text { events. } \\
\text { Unclear method for judging the causal } \\
\text { relationship between the adverse event and } \\
\text { death. }\end{array}$ \\
\hline $\begin{array}{l}\text { Landrigan et } \mathrm{al}^{7} \text { (used by } \\
\text { Makary and Daniel }{ }^{4} \text { and by } \\
\text { James }^{9} \text { ) }\end{array}$ & $\begin{array}{l}2341 \text { admissions to } 10 \text { North Carolina } \\
\text { hospitals from } 2002 \text { to } 2007\end{array}$ & 14 & $\begin{array}{l}\text { No stated method for judging the causal } \\
\text { relationship between preventable adverse event } \\
\text { and eventual death. }\end{array}$ \\
\hline $\begin{array}{l}\text { Classen et al }{ }^{8} \text { (used by } \\
\text { Makary and Daniel }{ }^{4} \text { and by } \\
\text { James }\end{array}$ & $\begin{array}{l}795 \text { admissions randomly selected from } \\
\text { hospitalisations of at least } 24 \text { hours from } \\
\text { October } 2004 \text { in three hospitals }\end{array}$ & 9 & $\begin{array}{l}\text { No distinction between preventable and } \\
\text { non-preventable adverse events. } \\
\text { No stated method for judging the causal } \\
\text { relationship between adverse event and } \\
\text { eventual death. }\end{array}$ \\
\hline $\begin{array}{l}\text { HealthGrades }{ }^{5} \text { (used by } \\
\text { Makary and Daniel }{ }^{4} \text { ) }\end{array}$ & $\begin{array}{l}\text { Hospital-acquired conditions identified using } \\
\text { Patient Safety Indicators and resulting } \\
\text { prevalence combined with estimates of the } \\
\text { mortality attributable to these conditions }\end{array}$ & 389576 & $\begin{array}{l}\text { Estimate depends on questionable values for } \\
\text { the attributable mortality associated with } \\
\text { hospital-acquired conditions. } \\
\text { This number of preventable deaths represents } \\
\text { over half of all inpatient deaths in the USA in a } \\
\text { year. }{ }^{17}\end{array}$ \\
\hline Leapfrog group ${ }^{10} \dagger$ & Similar to above & 206021 & $\begin{array}{l}\text { Estimate depends on questionable values for } \\
\text { the attributable mortality associated with } \\
\text { hospital-acquired conditions. } \\
\text { This number of preventable deaths represents } \\
\text { about } 30 \% \text { of all inpatient deaths in the USA } \\
\text { in a year. }{ }^{17}\end{array}$ \\
\hline
\end{tabular}

${ }^{*}$ As discussed in the text, none of these studies directly assessed the prevalence of preventable deaths. The several studies ${ }^{12}{ }^{13-15}$ that did focus on identifying preventable deaths all reported under $5 \%$ of all hospital deaths as preventable, leading to a 10 -fold lower estimate of deaths due to medical error.

†This estimate was not included by either Makary and Daniel ${ }^{4}$ or by James. ${ }^{9}$ It has been included because it uses similar methodology to the estimate from HealthGrades but does so with some refinements and more contemporary data.

occurred close to a death is not a sufficient basis for concluding that the error is the cause of death. Yet these studies do not have an explicit methodology for handing this situation-for distinguishing deaths where error is the primary cause from deaths where errors occurred but did not cause a fatal outcome.

A further problem with the basing estimates on studies that use adverse event and trigger tools of the type used by Makary and Daniel (and in the similar review by James ${ }^{9}$ ) is that they typically involve very small numbers of deaths. For instance, one study used a trigger tool approach to review 100 charts per quarter from each of 10 hospitals in North Carolina from January 2002 to December 2007. ${ }^{7}$ This study sought to detect any decline in adverse events that might have occurred as a result of patient safety efforts. In passing, the authors report that 14 adverse events were judged to have 'caused or contributed to a patient's death'. These 14 deaths represented $0.6 \%$ of the total patients in the study. Similarly, one US government report included three preventable deaths; ${ }^{11}$ another reported $12 .{ }^{6}$ One of the widely quoted peer-reviewed studies identified nine deaths. ${ }^{8}$ Any extrapolation that generalises from so few deaths (14 or fewer) to so many $\left(200000-400000^{4}{ }^{9}\right)$ surely warrants substantial scepticism.

The need for scrutiny is particularly important because when studies are designed specifically to identify preventable deaths, they typically report low rates. Studies that have reviewed inpatient deaths and asked physician reviewers to judge preventability have reported proportions under $5 \%$, typically in the range of $1 \%-3 \% .^{12-15}$ The largest and most recent of these studies $^{13}$ reported that trained medical reviewers judged $3.6 \%$ of deaths to have at least a $50 \%$ probability of being avoidable. 


\section{EPIDEMIOLOGICAL ERRORS}

While most of the studies used by Makary and Daniel did not have as their primary purpose the estimation of deaths due to medical errors, the estimate from HealthGrades did. This estimate, and a more recent one from the Leapfrog group ${ }^{10}$ (table 1), uses a methodology that depends on combining the frequency of hospital-acquired conditions (HACs), such as central line bloodstream infections and pressure ulcers, with estimates for the mortality attributable to these HACs. Some of these HACs include the PSIs produced by the US Agency for Healthcare Research and Quality. ${ }^{16}$

Using this methodology, HealthGrades estimated 389576 deaths due to preventable adverse events per year in the USA (circa 2000-2002). From 2000 to 2010 , the annual rate of inpatient deaths in the USA ranged from 715000 to $776000,{ }^{17}$ meaning that HealthGrades proposed that over 50\% of all inpatient deaths are preventable. The more recent Leapfrog produces a somewhat lower estimate of avoidable deaths in US hospitals each year-206 $021,{ }^{10}$ with the lower number reflecting deliberate avoidance of doublecounting deaths in patients who developed more than one HAC. Preventable conditions such as pressure ulcers, thromboembolism and healthcare-acquired infections occur, of course. They occur far more often than they should. They are profoundly distressing for patients and their families. But, saying that they account for $30 \%-50 \%$ of inpatient deaths flies in the face of clinical experience. It is likely instead that many patients die with, rather than of, these conditions.

\section{How could the estimated death toll be so wrong?}

The PSIs are problematic as a basis for estimating mortality rates attributable to healthcare-acquired conditions. A recent systematic review found that all but one of these PSIs have a positive predictive value of $<80 \%{ }^{18}$ and some developers of the indicators acknowledge that they have only moderate validity. ${ }^{19}$ A more fundamental challenge is a basic epidemiological one: confounding. Patients at risk of HACs are also those at increased risk of dying from their underlying conditions. For instance, in one analysis, patients who developed Clostridium difficile infection had a significantly higher baseline risk of death than did patients who never developed this HAC $(8.0 \%$ vs $1.8 \%$ baseline risk). ${ }^{20}$ This type of confounding makes it very hard to allocate aliquots of blame to failures of medical management versus the patient's underlying illnesses. Thus, when errors are followed by death, it is only rarely straightforward to adjudicate the extent to which error contributed to death.

If we acknowledge that the contribution that error makes to a particular fatal outcome is highly variable and often one of many factors implicated in a death, the fallacy of comparing deaths due to medical error with deaths due to the causes currently listed in the Center for Disease Control's current system becomes clear. That classificatory system lists causes of death firmly based either on tightly defined proximal causes (eg, suicide, currently the 10th leading cause of death in the USA) or on well-specified physiological disease processes (eg, heart disease, the first-leading cause ${ }^{21}$ ). Deaths due to medical error, on the other hand, have no such well-bounded properties: their definition(s) is elusive and changes (often rapidly) over time ${ }^{22}$ and they are only rarely the direct cause (as, eg, when a patient is given a massive overdose of an anaesthetic agent).

All of the estimates we critique involve another basic epidemiological error: they use crude extrapolations to populations that were not included in the original studies. For instance, the two US OIG reports focused on Medicare patients hospitalised for at least 24 hours. The most common reason for hospitalisation-accounting for around $10 \%$ of the total-is delivery of a live newborn. ${ }^{23}$ Yet, Medicare eligibility depends on age ( $\geq 65$ years) or having end-stage kidney disease. These populations include few patients likely to deliver a baby. Thus, the estimates of deaths due to medical error came from studies that did not include normal deliveries but are applied to a population (all US hospitalisations) in which this is the most common admission diagnosis. Similar issues apply to other populations such as psychiatric patients, rehabilitation stays and admissions for less than 24 hours. Even when these patients are excluded from the adverse event study, ${ }^{7}$ the extrapolation involves applying the risks of preventable deaths among medical and surgical patients to these much lower risk hospitalisations.

\section{WHY THE FUSS? WHAT HARM COULD COME FROM ESTIMATING SO MANY DEATHS DUE TO MEDICAL ERROR?}

Around 700000 deaths occur in US hospitals annually. ${ }^{17}$ Makary's and Daniel's estimate that over 250000 of those are preventable implies that around a third (or more) of inpatient deaths result from medical error or preventable adverse events. If, as studies that have actually studied preventable deaths have concluded, $3.6 \%$ is the more correct rate, then it means something like 25000 deaths might be averted each year by eliminating medical error-a far cry from 251454 . Every life avoidably lost is a tragedy. No one is disputing the need to improve safety. But does this 10 -fold difference in the death rate matter?

One could argue, as many did in the wake of the IOM estimate, that we should avoid picking apart estimates of mortality rates for medical error, since they draw attention to a much-neglected issue. This argument lies at the heart of one of the central tensions in the field of patient safety since its inception: the tendency to call for action on the basis of limited evidence. $^{24-26}$ The urge to do so may arise from the desire to make up for lost time-the many decades of exclusive focus in medical research on discovering 
new tests and treatments while neglecting the basic duty not to harm patients. But, it is an urge that must be kept in check.

First, patient safety needs to establish its scientific credentials. It does the field no favours if the basic epidemiological facts cannot be trusted. For a start, it means that the metrics of progress will be constantly disputed. ${ }^{27}$ After 16 years of sustained attention to improve patient safety and other aspects of healthcare quality, it is disappointing to find that some are claiming that the problem is fivefold bigger than previously announced. We need reliable measures of progress over time, just as any field does. If 'anything goes' as far as the metrics are concerned, we have no hope of demonstrating that all the investment and effort in patient safety are worth it-thus, discouraging further investment.

Second, the narrow focus on preventable death risks distracting attention from the many harmful consequences of failures to manage risks adequately in healthcare that do not result in death. ${ }^{2} 312$ 28-30 Just as most deaths do not involve medical error, most medical errors do not produce death-but they can still produce substantial morbidity, costs, distress and enduring suffering. Highlighting preventable deaths as the focus of patient safety efforts risks drawing resources away from many safety problems and many settings of care-including most non-hospital environments-where death is not the most relevant outcome. For instance, medication safety is universally regarded as one of the largest categories of safety problems; yet drug errors, though very common, do not usually result in fatal outcomes. ${ }^{31}$ Most pressure ulcers do not result in death, but they are a painful and miserable experience for patients. Does this mean that medication safety and pressure ulcers should not receive attention? Of course not. But, this is the risk of repeatedly focusing the attention of the public and policymakers on death as the sole outcome of interest.

\section{The bottomless well of medical error}

In listservs and blogs discussing the controversy over deaths due to medical error, we have encountered responses to any criticisms of the estimated death toll that take the form: "But those numbers don't even include...deaths due to unnecessary care, diagnostic errors, excessive radiation from overuse of radiologic investigations ...". In other words, the argument amounts to, "Even if the analysis did have some problems, it didn't include other important types of deaths due to medical error. So, the number is probably still about right". These additional potential causes of death due to medical error have some legitimacy. For instance, one of us (KGS) has estimated that about $5 \%$ of deaths in US hospitals involved missed diagnoses that, had they been detected prior to death, might have altered the fatal outcome. ${ }^{32}$ Chart review studies of preventable deaths make these potential deaths due to misdiagnosis difficult to identify since so few autopsies occur in most US hospitals.

That said, this is a very different approach in estimating deaths due to medical error from that of extrapolating from adverse event studies. This approach starts with identifying all the important types of medical errors that we can think of-diagnostic errors, underuse of beneficial therapies (eg, failure to follow guidelines for the management of coronary artery disease), overuse of non-beneficial ones and so on. Then, to generate a total, it combines the frequency of these errors with estimates of how often each causes death. Even putting aside the speculative nature of many of the inputs to such an estimate, this approach almost certainly hugely overestimate mortality attributable to error. A patient can have a diagnostic error in connection with one aspect of their care, a medication safety problem with another, and not receive guideline-concordant care for yet another condition. Each of these categories of medical error may have an associated attributable mortality. Yet, the patient can only die once. Adding up the attributable mortalities for every type of error will substantially overestimate deaths due to errors.

Another problem with "But we didn't even include $\mathrm{A}, \mathrm{B}$, and $\mathrm{C}$ when we counted up all the deaths due to medical error" is that this approach is unevenly applied. The same reasoning is not so assiduously pursued for other leading causes of death-arguing, for example, that many deaths from heart disease, stroke and kidney failure include cases of diabetes, which would therefore make it the leading cause of death.

If passionate advocates for reducing medical error want constantly to redraw the boundaries of death due to $\mathrm{X}$, others who are passionate about different diseases and determinants of health will do likewisean arms race of who can count the most deaths due to the object of their advocacy. We appreciate the need for passion to capture attention and kick-start efforts to improve healthcare. But, at some point, we need to roll up our sleeves and do the patient, scientific work of characterising the target problems and evaluating our progress over time. Constantly expanding the boundaries of what counts as a death due to medical error will not serve that goal, but improved reliability and validity will.

\section{CONCLUSION}

One of our missions as editors of BMJ Quality and Safety has been to elevate the scientific standards of efforts aiming to measure or improve safety and healthcare quality more broadly. Laudable enthusiasm for the goal to reduce suffering has always had to be tempered with adherence to rigorous methods. We do not want to disseminate ineffective patient safety strategies any more than we want inadequately tested new medications or surgical treatments. We also do not 
want to alienate key clinical partners in efforts to improve patient safety. Given their everyday clinical experiences, most healthcare professionals will strain to believe that their efforts to help patients in fact account for one-third of all hospital deaths. Given the basic flaws in the estimates that we and others have identified, it is not clear on what basis they could be persuaded otherwise. Parading dubious statistics instead has the effect of disengaging clinicians from what may appear to be a field lacking in credibility, damaging their confidence in interventions intended to improve safety and threatening professional-patient relationships.

We are deeply committed to improve patient safety and quality of care. Avoidable deaths and suffering can best be reduced by improving the evidence base and that must start with sound epidemiology. Without this, over time implausible estimates of deaths due to medical error will do more to erode the cause of patient safety than headline-friendly figures will do to help it.

Contributors KGS and MD-W contributed to the conception of the paper; they critically read and modified subsequent drafts and approved the final version. They are both editors at $B M J$ Quality and Safety.

Competing interests None declared.

Provenance and peer review Not commissioned; internally peer reviewed.

\section{REFERENCES}

1 Kohn LT, Corrigan J, Donaldson MS. To err is human: building a safer health system. Washington DC: National Academy Press, 2000.

2 McDonald CJ, Weiner M, Hui SL. Deaths due to medical errors are exaggerated in Institute of Medicine report. JAMA 2000;284:93-5.

3 Brennan TA. The Institute of Medicine report on medical errors-could it do harm? N Engl J Med 2000;342:1123-5.

4 Makary MA, Daniel M. Medical error-the third leading cause of death in the US. BMJ 2016;353:i2139.

5 HealthGrades quality study: patient safety in American hospitals. 2004. http://www.providersedge.com/ehdocs/ehr_ articles/Patient_Safety_in_American_Hospitals-2004.pdf (accessed 25 Sep 2016).

6 Department of Health and Human Services, Office of the Inspector General. Adverse events in hospitals: national incidence among medicare beneficiaries. OEI-06-09-00090. Washington DC, 2010. http://oig.hhs.gov/oei/reports/ OEI-06-09-00090.pdf

7 Landrigan CP, Parry GJ, Bones CB, et al. Temporal trends in rates of patient harm resulting from medical care. $N$ Engl J Med 2010;363:2124-34.

8 Classen DC, Resar R, Griffin F, et al. 'Global trigger tool' shows that adverse events in hospitals May be ten times greater than previously measured. Health Aff (Millwood) 2011;30: 581-9.

9 James JT. A new, evidence-based estimate of patient harms associated with hospital care. J Patient Saf 2013;9:122-8.

10 Austin M, Derk J. Lives Lost, Lives Saved: A Comparative Analysis of Avoidable Deaths at Hospitals Graded by The
Leapfrog Group 2016. http://www.hospitalsafetyscore.org/ media/file/LivesLostLivesSavedWhitePaper.pdf

11 Department of Health and Human Services, Office of the Inspector General. Adverse events in hospitals: case study of incidence among medicare beneficiaries in two selected counties. Washington DC, 2008. http://oig.hhs.gov/oei/reports/ OEI-06-08-00220.pdf

12 Hayward RA, Hofer TP. Estimating hospital deaths due to medical errors: preventability is in the eye of the reviewer. JAMA 2001;286:415-20.

13 Hogan H, Zipfel R, Neuburger J, et al. Avoidability of hospital deaths and association with hospital-wide mortality ratios: retrospective case record review and regression analysis. BMJ 2015;351:h3239.

14 Hogan H, Healey F, Neale G, et al. Preventable deaths due to problems in care in English acute hospitals: a retrospective case record review study. BMJ Qual Saf 2012;21:737-45.

15 Manaseki-Holland S, Lilford RJ, Bishop JR, et al. Reviewing deaths in British and US hospitals: a study of two scales for assessing preventability. BMJ Qual Saf 2016; doi:10.1136/ bmjqs-2015-004849.

16 Romano PS, Geppert JJ, Davies S, et al. A national profile of patient safety in U.S. hospitals. Health Aff 2003;22: 154-66.

17 Hall MJ, Levant S, DeFrances CJ. Trends in inpatient hospital deaths: national hospital discharge survey, 2000-2010. NCHS Data Brief 2013;118:1-8.

18 Winters BD, Bharmal A, Wilson RF, et al. Validity of the agency for health care research and quality patient safety indicators and the centers for medicare and medicaid hospital-acquired conditions: a systematic review and meta-analysis. Med Care 2016 Apr 25; [Epub ahead of print].

19 Romano PS, Mull HJ, Rivard PE, et al. Validity of selected AHRQ patient safety indicators based on VA national surgical quality improvement program data. Health Serv Res 2009;44:182-204.

20 Forster AJ, Taljaard M, Oake N, et al. The effect of hospital-acquired infection with Clostridium difficile on length of stay in hospital. CMAJ 2012;184:37-42.

21 Leading Causes of Death. Centers for Disease Control and Prevention. 2015. http://www.cdc.gov/nchs/fastats/ leading-causes-of-death.htm (accessed 25 Sep 2016).

22 Vincent C, Amalberti R. Safety in healthcare is a moving target. BMJ Qual Saf 2015;24:539-40.

23 Kowlessar NM, Jiang HJ, Steiner C. Hospital Stays for Newborns, 2011. Healthcare Cost and Utlization Project (HCUP) Statistical Briefs 2013. US Agency for Healthcare Research and Quality. http://www.hcup-us.ahrq.gov/reports/ statbriefs/sb163.pdf

24 Auerbach AD, Landefeld CS, Shojania KG. The tension between needing to improve care and knowing how to do it. N Engl J Med 2007;357:608-13.

25 Shojania KG, Duncan BW, McDonald KM, et al. Safe but sound: patient safety meets evidence-based medicine. JAMA 2002;288:508-13.

26 Wachter RM, Pronovost PJ. The 100,000 lives campaign: a scientific and policy review. Jt Comm J Qual Patient Saf 2006;32:621-7.

27 Shojania KG, Marang-van de Mheen PJ. Temporal trends in patient safety in the Netherlands: reductions in preventable adverse events or the end of adverse events as a useful metric? BMJ Qual Saf 2015;24:541-4. 


\section{Viewpoint}

28 Carroll AE. Death by Medical Error: Adding Context to Scary Headlines. New York Times. 15 August, 2016. http://www. nytimes.com/2016/08/16/upshot/death-by-medical-erroradding-context-to-some-scary-numbers.html?_r $=0$ (accessed 25 Sep 2016).

29 Shojania KG, Dixon-Woods M. Re: Medical error-the third leading cause of death in the US. BMJ 2016;353:i2139. http://www.bmj.com/content/353/bmj.i2139/rr-2154
30 Hogan H. The problem with preventable deaths. BMJ Qual Saf 2016;25:320-3.

31 Bates DW, Cullen DJ, Laird N, et al. Incidence of adverse drug events and potential adverse drug events. Implications for prevention. ADE Prevention Study Group. JAMA 1995;274:29-34.

32 Shojania KG, Burton EC, McDonald KM, et al. Changes in rates of autopsy-detected diagnostic errors over time: a systematic review. JAMA 2003;289:2849-56. 